\title{
A project management framework for small- and medium-sized entities: Accounting software implementation
}

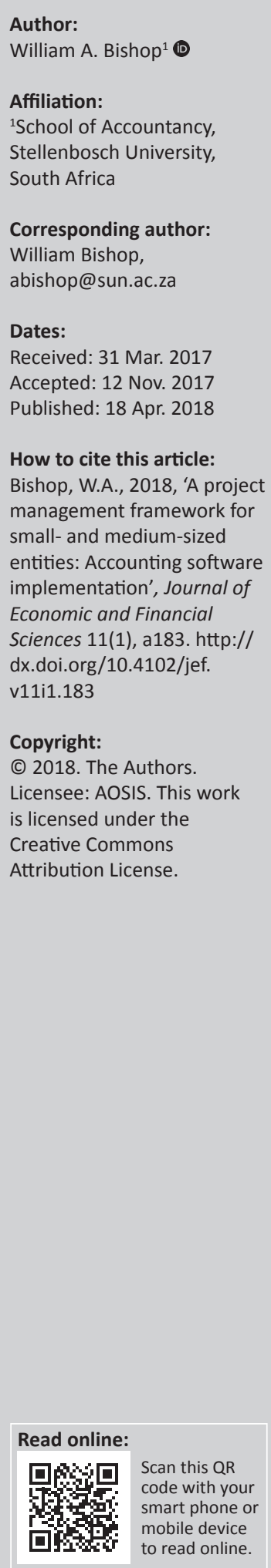

Small- and medium-sized entities (SMEs) continuously face the challenge of proper implementation of accounting packages. Not managing the package installation and configuration processes properly will result in the accounting software not working properly and not achieving the strategic goals of the SME. The purpose of this study was to examine, by means of an extensive literature review, the potential of PRINCE2 (Projects in Controlled Environments) as a project-management framework for application by SMEs during the implementation of new accounting software. The potential of scaling down PRINCE2 to a version usable to SMEs was investigated. PRINCE2 was found to be a suitable framework for use by SMEs in the implementation of accounting software packages, but only if tailored properly to incorporate the specific needs of the SME and adjusted to specifically address strategic alignment issues. Recommendations by other researchers on the weaknesses and shortcomings of the PRINCE2 framework were also investigated and included in the development of a new model for SMEs. This article contributes to the academic literature by providing it with a standard tailored version of PRINCE2 that can be used by SMEs in the implementation of new accounting software.

\section{Introduction}

During the implementation of new accounting software packages, proper project management tools are very important in order for the accounting package to be properly installed and for it to operate as a business system for small- and medium-sized entities (SMEs). Olugbode et al. (2008) describe a business system as all the tools, techniques and procedures that have to be used by the entity for data processing. It was found that project management tools are rarely used by smaller companies on smaller projects (Marcelino-Sádaba et al. 2014; Turner, Ledwith \& Kelly 2009). A lack of control over the implementation of accounting packages is another reason why small accounting packages fail to manage and deliver the required outputs for the business. Kruger and Rudman (2013) addressed how a framework such as Projects in Controlled Environments (PRINCE2) can be used to align the implementation of an accounting software package with a business's strategies, addressing what is commonly known as the information technology (IT) gap. PRINCE2 is a framework suitable for project management, but it focuses mainly on large implementation projects (Marcelino-Sádaba et al. 2014). The need therefore arose for a framework for smaller projects that can be used by SMEs during the implementation of small accounting packages to ensure alignment of business imperatives or strategies with the accounting package functionalities (Kruger 2012).

One of the main problems entities face when implementing new accounting software is failure to follow a controlled implementation approach (Kruger \& Rudman 2013). Many publications focus on the consequent failure of information systems (ISs) if proper project management principles are not followed (Kruger 2012; Umble, Haft \& Umble 2003). Reasons for failure include risks that are not identified and addressed during the implementation phase (Verner \& Evanco 2005), software not working as desired and strategic alignment not reached. This further leads to the accounting package not being configured properly and not operating in a way that enables the business to successfully manage its business system (Kruger 2012).

Many project management frameworks are available, and research has shown that following project management frameworks in the implementation of ISs contributes to strategic alignment (Kruger \& Rudman 2013) and addressing project risk (Marcelino-Sádaba et al. 2014). Little research is, however, available on specifically addressing additional challenges faced by SMEs 
when it comes to project management. Most frameworks that are available for project management are suitable for application by larger entities, but not suitable for use by SMEs (Turner et al. 2009), and a tailored version of PRINCE2, suitable for use by SMEs, is currently not available in the market. Reasons include additional challenges such as the complexity of frameworks, their generic nature and time constraints with regard to tailoring of models. A nonempirical approach in the form of an extended literature review was followed in this study and identified the options available to SMEs to overcome these additional challenges when selecting a project management framework. This study also develops a standard tailored version of PRINCE2, incorporating recommendations by other authors on addressing PRINCE2 shortcomings and weaknesses (Kruger \& Rudman 2013), which can be used by SMEs during accounting software implementation.

\section{Related literature}

Small- and medium-sized entities are a very important part of economies worldwide (Burgstaller \& Wagner 2015). In Europe, they are seen as the key sources of jobs, almost twothirds of jobs are produced by SMEs (Gama \& Geraldes 2012). Small- and medium-sized entities also develop the innovative entrepreneurial spirit of markets (Marcelino-Sádaba et al. 2014; Matejun 2014). Globally, SMEs are seen to be the foundation of economic growth and as a result find themselves in a competitive environment as they need to directly compete with larger entities in the same markets (Dasari, Jigeesh \& Prabhukumar 2015).

For SMEs to successfully compete and prevent their business systems from failing (Dwivedi et al. 2015), proper alignment of business strategies with IT strategies is key. Non-alignment of SMEs business strategies with IT strategies limits growth and ultimately survival ( $\mathrm{Li}$ et al. 2016). Good project management principles should be followed (Dasari et al. 2015) to successfully manage strategic alignment of an entity's business strategies with its newly installed accounting software to prevent failure (Dwivedi et al. 2015) and to assist in the implementation of new ISs.

In a recent study, it was found that SMEs are often in a position where the standard accounting package implemented does not meet their requirements. Accounting software packages should only be purchased if the functionalities that they provide meet the needs of the SME, but is still affordable (Bishop 2017); otherwise, if a generic software accounting package is installed that does not provide the required outputs for that SME, it will result in software failure (Dwivedi et al. 2015). The misalignment between generic software and strategic business imperatives is also commonly referred to as the IT gap (Kruger 2011).

Some authors argue that project management principles should include aspects of clear objectives, resource and work plans and progress monitoring (Umble et al. 2003). Other authors also mention that the greatest success of software implementation lies in the correct identification of project risk at the start of the project (Verner \& Evanco 2005). Marcelino-Sádaba et al. (2014) concluded in one of their studies on small firm projects that project risks often tend to play out during the initial and final stages of the projects. They found it to be because of a lack of oversight in these two stages. Identifying strategic business objectives and incorporating them into the management of software implementation projects for SMEs are critical for successful software implementation, especially because most SMEs find themselves in a competitive environment in which, to survive, they need to reduce costs as far as possible (Dasari et al. 2015). Increased competition between companies adds pressure on businesses to have a well-functioning, competitive IT system but at the same time lowering costs on all possible levels (Umble et al. 2003), and financial resources of SMEs are already lower than larger entities (Falkner \& Hiebl 2015). Small- and medium-sized entities often also do not invest in larger projects with higher risk because of the cost implication, resulting in missed opportunities (Gama \& Geraldes 2012).

Little has, however, been published on strategic alignment and project management within SMEs (O'Sheedy 2012). The need arises to address this and to identify reasons why SMEs tend to not generally use proper project management frameworks during the implementation of new software (Marcelino-Sádaba et al. 2014). It is widely argued that by following proper project management techniques for projects like these, it leads to better quality, reduced time and lower costs (Dasari et al. 2015; Hermida, De la Fuente \& García 2016; Kruger \& Rudman 2013).

Various project management frameworks are available to entities to assist in IS project management (i.e. PMBoK Project Management Body of Knowledge, PRINCE2, ICB IPMA Competence Baseline) (Marcelino-Sádaba et al. 2014). These frameworks are, however, often more suitable for implementation by larger entities because of their complexity (Marcelino-Sádaba et al. 2014) and do not specifically address methods that can be used by SMEs. Small- and mediumsized entities also often do not have access to project managers with the required technical skills required for software implementation (Li et al. 2016; O'Sheedy 2012).

To obtain a workable project management framework for SMEs, it is important to identify the characteristics of the projects that need to be managed. According to MarcelinoSádaba et al. (2014), projects of SMEs have some of the following common features and needs to be managed:

- The project and the project team are small.

- It is mainly internally managed.

- The objectives are clearly identified.

- It is mostly related to day-to-day activities of the SME.

PRINCE2, initially developed as a UK government standard, is a methodology that is designed to assist project managers in the effective management of projects and 
resource management (Kruger \& Rudman 2013). PRINCE2 is an example of a framework that is more suitable for use by medium to large entities, rather than for smaller projects because of its bureaucratic nature (Marcelino-Sádaba et al. 2014; Turner et al. 2009). Reasons that have been provided for this include limited or unskilled staff usually employed by SMEs, limited resources available to SMEs and the complexity of the framework (Marcelino-Sádaba et al. 2014). However, both the PRINCE2 framework and authors, such as Hanney and Savin-Baden (2013), state that the framework is fully scalable and, if done correctly, can be used on smaller projects as well. This can, however, be a very timely and costly exercise, as there are almost 40 different activities that will need to be looked into and adjusted to suit the implementation requirements of the SME (O'Sheedy 2012). Small- and medium-sized entities often follow a low-cost strategy (Lee, Shin \& Park 2012) that will result in them finding the scaling down of a framework such as PRINCE2 too costly and not beneficial. Wynn et al. (2009) indicate that some authors are of the view that the time spent on tailoring PRINCE2 will not add sufficient value. However, SMEs might find an already scaled-down version that requires minor or no tailoring more appealing. Although some authors argue that the PRINCE2 methodology is not suitable for SMEs because of its bureaucratic nature (Turner et al. 2009), others are of the opinion that if scaled down correctly, PRINCE2 can be valuable to SMEs in project management by using only the processes that are applicable and required in the relevant situation (Wynn et al. 2009).

The purpose of this study is to look into the tailoring of PRINCE2 into a scaled-down version that can be used by SMEs specifically during the implementation of new accounting software. A tailored version of the model was consequently developed. An overview of the PRINCE2 methodology, on which this tailoring was based, follows:

\section{An overview of the Projects in Controlled Environments methodology}

Saad et al. (2013) explain that there are normally six areas of project management: costs, timescales, scope, quality, risks and benefits:

- Costs: Small- and medium-sized entities often find themselves in a competitive environment in which, to survive, they need to reduce costs as far as possible (Umble et al. 2003). The cost of the software implementation project will therefore also play a role in software implementation by SMEs.

- Timescales: It is important for all projects to be managed within a specified timeline. The moment that the project exceeds the original timeline, costs, scope, quality and project risk are directly affected (Saad et al. 2013).

- Scope: It is essential to define the scope of the software implementation project accurately. The project manager should firstly have a clear understanding of what should be included in the project, in other words packages, functionalities, customisation requirements and so forth.
This should be clearly laid out by the project manager to prevent unnecessary costs and missed deadlines (Saad et al. 2013).

- Quality: It is essential that software packages implemented by SMEs should have sufficient functionalities to successfully drive the business system and attain the business imperatives of the SME (Kruger 2012). Therefore, the installed software program should work for the purposes for which it was installed (Saad et al. 2013).

- Risks: All projects come with risk and it is essential that the risk an SME is willing to take in the implementation of software packages is clearly understood and addressed by the implementation plan (Saad et al. 2013).

- Benefits: Lastly, the software package installed by the SME must benefit the SME in all possible ways. The package should drive the business imperatives of the SME (Kruger 2012).

Projects in Controlled Environments is categorised as a generic framework built on the above-mentioned areas of importance (Saad et al. 2013). The framework assists project managers in project management, but needs to be tailored to suit individual projects (Viergever 2014). The framework was developed over some years from insights into many projects (Kruger \& Rudman 2013).

The PRINCE2 methodology is built on seven principles and consists of seven themes and seven processes (Figure 1) that are aimed at addressing the above-mentioned six areas of project management (Siegelaub 2004). Details of the seven principles, themes and processes are attached as Appendix 1.

Figure 1 is an illustration of the PRINCE2 processes.

\section{Tailoring potential of Projects in Controlled Environments}

In a study conducted by Wynn et al. (2009), certain processes of PRINCE2 were tailored for a specific project on the replacement of software of a small- and medium-sized financial service company, Allpay.net. It is important to note that in their study, the PRINCE2 model was not tailored in such a way that other companies will be able to use it, but

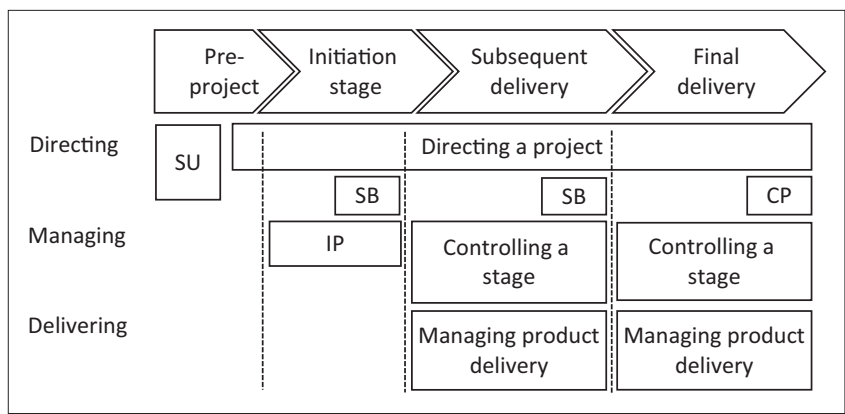

Source: Siegelaub, J.M., 2004, How PRINCE2 can complement PMBOK ${ }^{\circledR}$ guide and your PMP $\circledast$ APMG-International, viewed 30 October 2017, from http://ebooks.franciscomedina.net/ taller_pmbok_prince2/prince2-complement-pmbok-pmp.pdf

FIGURE 1: Projects in Controlled Environments process model. 
that it was rather adjusted to fit the needs of Allpay.net and recommendations were merely provided. The biggest challenge for Allpay.net was to integrate and maintain different in-house-developed software packages. The project team, consisting of only three staff members, adjusted some of the PRINCE2 processes in a way that addressed the scope and scale of the proposed project. This entailed using only a selection of the PRINCE2 proposed processes (Wynn et al. 2009). Recommendations made from their conclusions included the following (Wynn et al. 2009):

- Selectively use the main PRINCE2 processes to only include processes that address the required outcomes of the individual project.

- Combine certain activities from the starting up, initiating and directing processes into one brief document. Activities include the business case, brief, approach and quality plan.

- Minimise all other logs to only keep crucial logs, such as a risk $\log$.

- Make use of Microsoft Project for purposes of planning the project.

- Where possible, only make use of one stage rather than various stages. This enables a project team to exclude the managing stage boundaries process from the entire project.

- Only include the process of managing project delivery if really necessary.

- Make use of highlight, checkpoint and exception reports to address issues during the course of the project lifecycle.

- Selectively use the activities included in the process of closing a project. Ensure that project closure approval by the project board and a final project closure report are included.

In the book, Tailoring PRINCE2 (Office of Government Commerce 2004), it is also discussed how PRINCE2 can be tailored to suit smaller projects where a limited number of staff is involved. An example was provided of a project for a small company with limited staff. The book does not provide a tailored version of PRINCE2, but rather provides the reader with notes and recommendations on how it can be tailored. Conclusions reached from the small project included the following (Office of Government Commerce 2004):

- Selectively use the main PRINCE2 processes to only include processes that address the required outcomes of the individual project.

- Combine certain activities from the starting up, initiating and directing processes into one brief document. Activities include the business case, brief, approach and quality plan.

- Where possible, only make use of one stage rather than various stages. This enables a project team to exclude the managing stage boundaries process from the entire project.

- Only include the process of managing project delivery if really necessary.
- Make use of highlight, checkpoint and exception reports to address issues during the course of the project lifecycle.

- Selectively use the activities included in the process of closing a project. Ensure that project closure approval by the project board and a final project closure report are included.

One of the PRINCE2 principles is that the methodology be tailored to suit the needs of the specific project. Tailoring for the purposes of PRINCE2 is defined as those measures taken during the tailoring of the framework that ensure a sufficient level of governance, planning and control (Murray 2011:6).

Table 1 illustrates the focus areas of an entity during the adoption and tailoring of PRINCE2. Embedding refers to the adoption of PRINCE2 by the entity as a whole (Murray 2011:6).

The above literature study shows that the tailoring of PRINCE2 for SMEs is possible. Both Wynn et al. (2009) and the book, Tailoring PRINCE2 (Office of Government Commerce 2004), highlighted how different processes of PRINCE2 can be tailored for specific projects, but an actual standard tailored version of PRINCE2 for the implementation of accounting software was never developed by neither authors, but rather recommendations made on how tailoring can be done for each project. As the tailoring process might be timely and costly for SMEs, the need arises for a standard tailored version of PRINCE2 that can be used by SMEs, with the possibility of further minor tailoring if needed.

In our study, the findings from both the book and Wynn et al. (2009) were used to develop a standard tailored version of the PRINCE2 model that can be followed by SMEs. Further to this, our new model also includes additional steps to address the shortcomings and weaknesses of the PRINCE2 framework identified by Kruger and Rudman (2013). Their study specifically addressed issues regarding the alignment of business processes with application software functionality that will be of great value for SMEs if built into the model.

\section{Research methodology}

A non-empirical approach in the form of an extended literature review was followed in this study. Extended literature reviews were conducted by inspecting peer-

TABLE 1: Areas of focus during both Projects in Controlled Environments adoption and tailoring.

\begin{tabular}{|c|c|}
\hline $\begin{array}{l}\text { Embedding (conducted by the } \\
\text { organisation to adopt PRINCE2) }\end{array}$ & $\begin{array}{l}\text { Tailoring (conducted by the project } \\
\text { management team to adapt the method } \\
\text { to the context of a specific project) }\end{array}$ \\
\hline \multicolumn{2}{|l|}{ Focus on } \\
\hline $\begin{array}{l}\text { - Process responsibilities } \\
\text { - Scaling rules or guidance (e.g. } \\
\text { scorecard) } \\
\text { - Ttandards (templates, definitions) } \\
\text { - Iraining and development } \\
\text { - Togration with business processes } \\
\text { - Process assurance }\end{array}$ & $\begin{array}{l}\text { - Adapting the themes (through } \\
\text { strategies and controls) } \\
\text { - Incorporating specific terms or language } \\
\text { - Revising product descriptions for } \\
\text { management products } \\
\text { - Revising role descriptions for PRINCE2 } \\
\text { project roles } \\
\text { - Adjusting processes to match the above }\end{array}$ \\
\hline \multicolumn{2}{|c|}{$\begin{array}{l}\text { Source: Murray, A., 2011, White paper on PRINCE2 in one thousand words, vol. 2, The } \\
\text { Stationery Office, viewed } 30 \text { October 2017, from http://www.best-management-practice. } \\
\text { com/gempdf/PRINCE2_in_One_Thousand_Words.pdf }\end{array}$} \\
\hline \multicolumn{2}{|l|}{ RINCE2, Projects in Controlled Environments } \\
\hline
\end{tabular}


reviewed and non-peer-reviewed academic articles with empirical content, published conference papers, theses and dissertations, white papers, popular articles, academic books and published frameworks. A similar research methodology, also in the form of an extended literature review, was followed in the field of project management research conducted by Kruger and Rudman (2013) and by Goosen and Rudman (2013). In their study, they developed an integrated framework to implement IT governance principles at a strategic and operational level for mediumto large-sized businesses. Hermida et al. (2016) also followed a similar methodology in the development of a roadmap for the implementation of a project management model.

The following detailed methodology was followed in order to provide SMEs with a scaled-down version of PRINCE2 that can be used, after minor tailoring, in the implementation of their accounting software packages:

1. A literature review was performed on PRINCE2 as a project management framework to obtain an understanding of the theoretical concepts of the framework. An overview is provided in Appendix 1 of the key processes and activities that are required when following this framework.

2. The literature review in the 'Related literature' section included looking into the potential of PRINCE2 to be scaled down (tailored) in order for it to be applied by SMEs.

3. Based on the results of the literature review in the 'Related literature' section on the tailoring potential of PRINCE2: tailoring was done on the PRINCE2 framework in such a way that it is suitable for SMEs to use in the management of smaller projects, bearing in mind that minor tailoring might still be required to address specific project requirements. This is laid out in the 'Tailoring of PRINCE2 for small and medium sized entities' section.

4. Recommendations on weaknesses and shortcomings of the PRINCE2 framework when using it for the implementation of software were also researched.

5. The above-mentioned recommendations on weaknesses and shortcomings of PRINCE2 were scrutinised and filtered for possible inclusion in the standard tailored version of PRINCE2 developed through this research. These recommendations were included in the tailored version that was developed by this research (point 6).

6. A final tailored version of PRINCE2 was developed that can be used by SMEs in the implementation of accounting software as a business system. This tailored version was developed by incorporating the results of the abovementioned literature reviews.

The new scaled-down version of PRINCE2 that was developed in this study was based on the current PRINCE2 theory as well as recommendations on shortcomings and weaknesses of PRICNE2 identified through extended literature review.

\section{Tailoring of Projects in Controlled Environments for small- and medium-sized entities}

Turner, Ledwith and Kelly (2012) indicate that SMEs require management processes that are flexible and not as complicated to apply and are therefore not likely to make use of formal project management techniques. However, it is also concluded that SMEs that do make use of project management tools make use of status reports to track time and costs, manage risks and detail work structures (Turner et al. 2012).

\section{Tailoring of Projects in Controlled Environments Tailoring of Projects in Controlled Environments themes}

By considering both the literature review conducted in the 'Related literature' section and best management practices contained in the PRINCE2 methodology, when tailoring PRINCE2, it is important to still comply with some of the themes of PRINCE2 (these themes are listed as part of the overview in Appendix 1). Following best practices is required to retain the integrity of the project (Ferguson \& Consulting 2011; Hermida et al. 2016).

The considerations that have been taken into account during the tailoring of the PRINCE2 themes for smaller projects are as follows:

- It is essential that the cost and benefits of the project are still being considered throughout the project lifecycle to conclude on the feasibility of the project.

- A project manager and project board member (as a minimum) should be appointed with clearly assigned responsibilities.

- The quality of the end product should be controlled throughout the project.

- Keeping risk logs is essential to enable the project manager to react to deviations from the original project plan.

- The project plan should include detailed timelines, cost estimates, resources that will be used and the expected deliverables of the project.

- The project board member (independent member from the project manager) should be in charge of all high-level decisions.

- The project plan should be revisited throughout the project lifecycle and a progress report should be kept to keep track of the project progress.

\section{Tailoring of Projects in Controlled Environments processes}

Based on the literature review performed on project management in the 'Related literature' section, it is clear that, for smaller projects, a need for fewer processes and activities arises. It is therefore recommended that certain activities of 
TABLE 2: Recommendations for small- and medium-sized entities considering using Projects in Controlled Environments.

\begin{tabular}{|c|c|c|}
\hline Process & Activity & $\begin{array}{c}\text { Recommendation } \\
\text { (key) }\end{array}$ \\
\hline \multirow[t]{6}{*}{$\begin{array}{l}\text { Starting up a project } \\
\text { (SU) }\end{array}$} & $\begin{array}{l}\text { 1. Appoint the project board and the } \\
\text { project manager }\end{array}$ & (A) \\
\hline & 2. Capture previous lessons learnt & (B) \\
\hline & $\begin{array}{l}\text { 3. Design and appoint the project } \\
\text { management team }\end{array}$ & (A) \\
\hline & 4. Prepare the outline business case & (C) \\
\hline & $\begin{array}{l}\text { 5. Select the project approach and } \\
\text { assemble the project brief }\end{array}$ & (C) \\
\hline & 6. Plan the initiation stage & (D) \\
\hline \multirow{5}{*}{$\begin{array}{l}\text { Directing a project } \\
\text { (DP) }\end{array}$} & 1. Authorise initiation & $(E)$ \\
\hline & 2. Authorise the project & $(E)$ \\
\hline & 3. Authorise a stage or exception plan & $(E)$ \\
\hline & 4. Give ad hoc direction & $(\mathrm{E})$ \\
\hline & 5. Authorise project closure & (I) \\
\hline \multirow[t]{7}{*}{$\begin{array}{l}\text { Initiating a project } \\
\text { (IP) }\end{array}$} & $\begin{array}{l}\text { 1. Prepare the risk management } \\
\text { strategy }\end{array}$ & (C) \\
\hline & $\begin{array}{l}\text { 2. Prepare the configuration } \\
\text { management strategy }\end{array}$ & (C) \\
\hline & $\begin{array}{l}\text { 3. Prepare the communication } \\
\text { management strategy }\end{array}$ & (C) \\
\hline & 4. Set up the project controls & (C) \\
\hline & 5. Create the project plan & (C) \\
\hline & 6. Refine the business case & (C) \\
\hline & $\begin{array}{l}\text { 7. Assemble the project initiation } \\
\text { documentation }\end{array}$ & (D) \\
\hline \multirow{8}{*}{$\begin{array}{l}\text { Controlling a stage } \\
\text { (CS) }\end{array}$} & 1. Authorise a work package & (G) \\
\hline & 2. Review a work package status & (G) \\
\hline & 3. Receive completed work packages & (G) \\
\hline & 4. Review the stage status & (G) \\
\hline & 5. Report highlights & (G) \\
\hline & $\begin{array}{l}\text { 6. Capture and examine issues and } \\
\text { risks }\end{array}$ & (G) \\
\hline & 7. Escalate issues and risks & (G) \\
\hline & 8. Take corrective action & (G) \\
\hline \multirow{3}{*}{$\begin{array}{l}\text { Managing product } \\
\text { delivery (MP) }\end{array}$} & 1. Accept a work package & (G) \\
\hline & 2. Execute a work package & (G) \\
\hline & 3. Deliver a work package & (G) (I) \\
\hline \multirow{5}{*}{$\begin{array}{l}\text { Managing stage } \\
\text { boundary (MS) }\end{array}$} & 1. Plan the next stage & $(F)$ \\
\hline & 2. Update the project plan & (F) \\
\hline & 3. Update the business case & (F) \\
\hline & 4. Report stage end & (F) (H) \\
\hline & 5. Produce an exception plan & (F) \\
\hline \multirow{5}{*}{$\begin{array}{l}\text { Closing a project } \\
\text { (CP) }\end{array}$} & 1. Prepare planned closure & (।) \\
\hline & 2. Prepare premature closure & (I) \\
\hline & 3. Hand over products & (I) \\
\hline & 4. Evaluate the project & (I) \\
\hline & 5. Recommend project closure & (I) \\
\hline
\end{tabular}

Source: Office of Government Commerce, 2005, Managing successful projects with PRINCE2, The Stationery Office, UK

different processes are combined, certain processes are simplified and unnecessary activities are removed.

Table 2 was developed from the literature review findings in the 'Related literature' section and best management practices. It lists recommendations for SMEs considering using PRINCE2 during the implementation of accounting software.

\section{Recommendations}

Key Recommendation:

A The project board could consist of one person, but should have the highest level of authority and will ultimately be approving the project and making high-level decisions on the project. The project board member should, however, be independent of the project manager in order to review work and make high-level decisions. Roles and responsibilities of the board, manager and other team members should be clearly laid out. It is important to have a team member with sufficient IT knowledge, either an external supplier or internal employee with IT knowledge, as part of the project team.

B These activities will also be important activities to consider for small and medium projects.

C It is recommended that these activities be combined into one initiating stage as far as possible, rather than having a separate starting up and initiating stage. It is also recommended by Ferguson and Consulting (2011) to combine these two processes for smaller projects. It is further recommended to assemble one project brief document that outlines the business case, decide on the projectapproach, setout the frequency of communications that will take place between the project manager and the project board, set controls for project review and risk identification, and document the required product quality.

D These activities fall away because of the initiating stage and the starting up stage being combined into one initiating stage and the project plan being combined with the project initiation document in one project brief document.

E Authorisation and decision-making are done throughout the project lifecycle by the project board member(s).

$\mathrm{F}$ Based on the literature review reported on in the 'Tailoring potential of Projects in Controlled Environments' section, it is recommended that smaller projects, as far as possible, only include one main stage. This will enable all managing stage boundaries to be excluded by SMEs implementing small accounting packages. This should, however, only be done if it is possible and feasible for the specific project.

G Because of the recommendation of only having one main stage, it is recommended that activities from the managing product delivery and controlling a stage processes be combined into one controlling and delivering a project stage. Ferguson and Consulting (2011) also recommend this.

$\mathrm{H}$ Include this activity in the completing of a project stage.

I Combine this activity with the completing of a project stage.

\section{Implementing additional recommendations because of shortcomings and weaknesses identified within Projects in Controlled Environments by previous authors}

As a tailored PRINCE2 is recommended for projectmanagement purposes by SMEs, it is also important to include recommendations for shortcomings in the framework that have already been identified by previous authors. The study conducted by Kruger and Rudman (2013) concluded in a list of recommendations to address shortcomings and 
TABLE 3: Recommendations for addressing shortcomings and weaknesses of Projects in Controlled Environments.

\section{Recommendation category Recommendation description}

\begin{tabular}{|c|c|}
\hline Strategic alignment & $\begin{array}{l}\text { Misalignment between an entity's strategic business } \\
\text { objectives (set by management) and its information } \\
\text { systems (managed by IT) is formally defined as the IT } \\
\text { gap (Bishop 2017). Because of this IT gap, it is essential } \\
\text { that persons with both a business and an IT background } \\
\text { form part of the project team. Team members that do } \\
\text { not have sufficient experience should be mentored by } \\
\text { other team members. It is further recommended that } \\
\text { the project manager and project board member also } \\
\text { have a good understanding of the business system and } \\
\text { IT needs. This enables effective communication } \\
\text { between the IT team and top management. }\end{array}$ \\
\hline Testing of functionalities & $\begin{array}{l}\text { Testing of the functionalities of the software package by } \\
\text { end users should be conducted at the end of the project } \\
\text { before the software is implemented. It is important for } \\
\text { the end product to be tested by the users that will be } \\
\text { working with the program to ensure that the program is } \\
\text { working as it should and that functionalities achieve the } \\
\text { desired outcomes as required by the business } \\
\text { imperatives of the entity. }\end{array}$ \\
\hline $\begin{array}{l}\text { Competencies of team } \\
\text { members }\end{array}$ & $\begin{array}{l}\text { It is important that training and coaching are available } \\
\text { to team members or new project managers to ensure } \\
\text { that all members forming part of the project have the } \\
\text { necessary competencies to reach the required } \\
\text { objectives of the project. }\end{array}$ \\
\hline Communication & $\begin{array}{l}\text { Communication structures should be in place between } \\
\text { team members, the project manager and the project } \\
\text { board member to ensure that issues identified during } \\
\text { the course of the project are immediately } \\
\text { communicated and acted upon through the correct } \\
\text { channels. }\end{array}$ \\
\hline $\begin{array}{l}\text { Effective tailoring of the } \\
\text { PRINCE2 methodology } \\
\text { during the planning stage }\end{array}$ & $\begin{array}{l}\text { It is important to note that the methodology should still } \\
\text { be tailored during the project planning stage to ensure } \\
\text { that it addresses the specific requirements of the entity, } \\
\text { more specifically, that it is in line with the required } \\
\text { business imperatives that the entity strives towards. The } \\
\text { project brief and planning documentation should } \\
\text { specifically address and include these business } \\
\text { imperatives and the functionalities required to achieve it. }\end{array}$ \\
\hline People skills & $\begin{array}{l}\text { Team members and project managers should have good } \\
\text { people skills in order for them to successfully work } \\
\text { together. Although SMEs might have limited staff, it is } \\
\text { still important to use individuals with good people skills } \\
\text { to form part of the project team. }\end{array}$ \\
\hline
\end{tabular}

Source: Based on Kruger, W. \& Rudman, R., 2013, 'Strategic alignment of application software packages and business processes using PRINCE2', The International Business \& Economic packages and business processes using PRINCE2, The International Business \& Economics ac.za/handle/10019.1/85449

IT, information technology; PRINCE2, Projects in Controlled Environments; SMEs, small- and medium-sized entities.

TABLE 4: Basis of Projects in Controlled Environments for small- and mediumsized entities.

\begin{tabular}{lccccc}
\hline Principles & \multicolumn{5}{c}{ Themes } \\
\cline { 2 - 5 } & $\begin{array}{l}\text { Planning Objectives } \\
\text { of project }\end{array}$ & Organisation Quality & $\begin{array}{c}\text { Risk } \\
\text { management }\end{array}$ & Changes \\
\hline $\begin{array}{l}\text { Continued } \\
\text { alignment } \\
\text { (objectives } \\
\text { and } \\
\text { deliverables) }\end{array}$ & $\mathrm{X}$ & $\mathrm{X}$ & $\mathrm{X}$ & $\mathrm{X}$ \\
$\begin{array}{l}\text { Learn from } \\
\text { experience }\end{array}$ & $\mathrm{X}$ & & & & \\
$\begin{array}{l}\text { Defined } \\
\text { roles and } \\
\text { responsibilities }\end{array}$ & $\mathrm{X}$ & & & $\mathrm{X}$ & \\
$\begin{array}{l}\text { Authorisation } \\
\text { by board } \\
\text { member(s) }\end{array}$ & & $\mathrm{X}$ & & & \\
\hline
\end{tabular}

Note: The new PRINCE2 for SMEs model are detailed in Figure 2.

PRINCE2, Projects in Controlled Environments; SMEs, small- and medium-sized entities.

weaknesses in the PRINCE2 framework. It specifically addresses issues regarding the alignment of business processes with application software functionality (Kruger \& Rudman 2013). These recommendations were investigated and are summarised in Table 3 and filtered for recommendations that will also apply to SMEs for smaller software implementation projects.

\section{Tailored version of Projects in Controlled Environments for small- and medium-sized entities}

Following the recommendations made earlier, a standard tailored version of PRINCE2 for SMEs was developed. During this development, the recommendations for smaller projects and the recommendations for addressing weaknesses and shortcomings have been taken into account and incorporated in the development of a standard smaller version of PRINCE2.

Projects in Controlled Environments for SMEs is also based on the seven principles and themes of PRINCE2, but distilled to be accessible to SMEs. The new model was consequently built on the adjusted principles and themes mapped to form the basis of the model as showed in Table 4 .

\section{Conclusion}

For SMEs to successfully compete and prevent its business system from failure, proper alignment of business strategies with IT strategies is necessary during the software implementation process. Not following a structured methodology to manage the software implementation process was identified as a reason for software failure (Dwivedi et al. 2015).

This study highlighted the importance of making use of a structured framework for project management and indicated that PRINCE2, if scaled down, can be a valuable framework for use by SMEs during the implementation of small accounting software packages.

Projects in Controlled Environments as a project-management framework was researched for its suitability for SMEs to use during software implementation. In this study, case studies of small projects where some tailoring were done on PRINCE2 processes were reviewed and used to develop a shortened, standard version of PRINCE2 that can be used by SMEs during software implementation projects. Recommendations for improvement of weaknesses and shortcomings in the PRINCE2 framework were also obtained from relevant literature, filtered and included in this shortened version of PRINCE2 for SMEs.

From the literature review and development of a shortened version of PRINCE2, it was found that PRINCE2 as a framework is currently too bureaucratic for use by SMEs. It was further identified that the framework lacked sufficient activities to specifically address strategic alignment issues. It was concluded that if PRINCE2 is tailored properly and adjusted with certain recommended improvements, it can be a valuable framework for use by SMEs.

Other than examples of how some of the PRINCE2 processes were tailored for specific projects, this study contributes to the literature by providing SMEs with a general shortened version of PRINCE2 that also addresses shortcomings and 


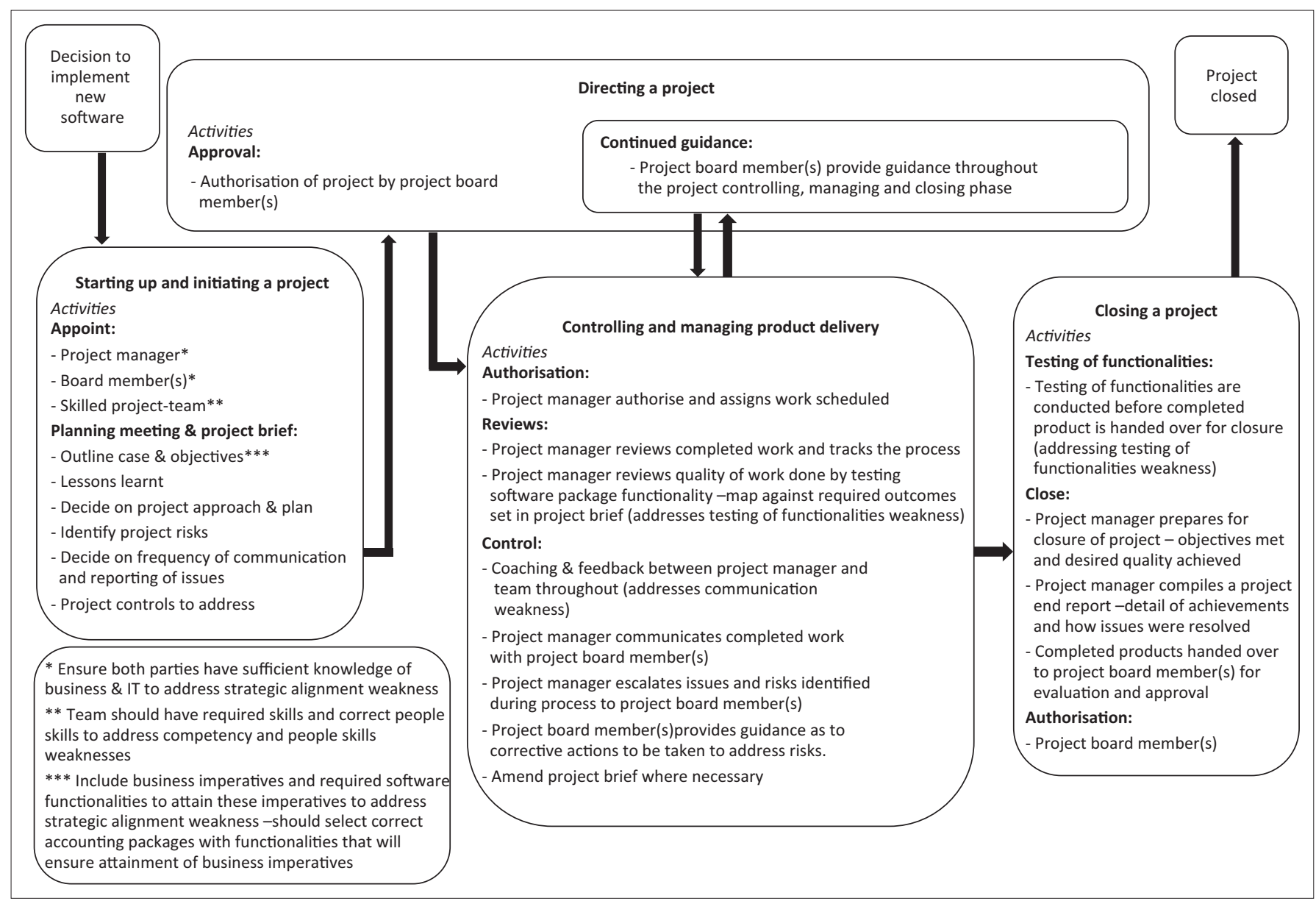

FIGURE 2: Projects in Controlled Environments for small- and medium-sized entities (accounting software implementation) - tailored process model.

weaknesses in the PRINCE2 model. This model can be used by SMEs in the implementation of new accounting software. This shortened version, as shown in Figure 2, will save SMEs time and cost as the tailoring of PRINCE2 is often not done by SMEs because of the time and cost it entails. Further empirical research can be conducted in which the model is tested for its successful implementation.

\section{Acknowledgements Competing interests}

The author declares that he has no financial or personal relationships which may have inappropriately influenced him in writing this article.

\section{References}

Bishop, W.A., 2017, 'Addressing the challenge of strategic alignment faced by small and medium-sized entities during the selection of accounting software packages', International Business \& Economics Research Journal 16(1), 31-55.

Burgstaller, J. \& Wagner, E., 2015, 'How do family ownership and founder management affect capital structure decisions and adjustment of SMEs?: Evidence from a bankbased economy', The Journal of Risk Finance 16(1), 73-101. https://doi.org/ 10.1108/S1479-3563(2012)000012B005

Dasari, S., Jigeesh, N. \& Prabhukumar, A., 2015, 'Analysis of project success issues: The case of a manufacturing SME', IUP Journal of Operations Management 14(1) 32-38, viewed 06 March 2018, from http://search.ebscohost.com/login.aspx?dir ect $=$ true \&db=bth\&AN=101858011\&site=ehost-live

Dwivedi, Y.K., Wastell, D., Laumer, S., Henriksen, H.Z., Myers, M.D., Bunker, D. et al. 2015 , 'Research on information systems failures and successes: Status update and future directions', Information Systems Frontiers 17(1), 143-157. https://doi. org/10.1007/s10796-014-9500-y
Falkner, E.M. \& Hiebl, M.R.W., 2015, 'Risk management in SMEs: A systematic review of available evidence', The Journal of Risk Finance 16(2), 122-144. https://doi. org/10.1108/JRF-06-2014-0079

Ferguson, C. \& Consulting, N., 2011, White paper on PRINCE2 ${ }^{\circledR}$ for small-scale projects, vol. 2, The Stationery Office, viewed 30 October 2017, from https://shop. axelos.com/gempdf/PRINCE2_Small_Scale_Projects_White_Paper.pdf

Gama, A.P.M. \& Geraldes, H.S.A., 2012, 'Credit risk assessment and the impact of the New Basel Capital Accord on small and medium-sized enterprises: An empirical analysis', Management Research Review 35(8), 727-749. https://doi.org/ 10.1108/01409171211247712

Goosen, R. \& Rudman, R., 2013, 'An integrated framework to implement IT governance principles at a strategic and operational level for medium- to large-sized South African businesses', International Business \& Economics Research Journal 12(7), 835-854, viewed 01 October 2015, from http://cluteinstitute.com/ojs/index.php/ IBER/article/view/7972/8026

Hanney, R. \& Savin-Baden, M., 2013, 'The problem of projects: Understanding the theoretical underpinnings of project-led PBL', London Review of Education 11(1), 7-19, https://doi.org/10.1080/14748460.2012.761816

Hermida, D., De la Fuente, D. \& García, F., 2016, 'Roadmap for the implementation of a project management model in a SME of engineering and turn-key supply of
industrial equipment', Brazilian Journal of Operations \& Production Management industrial equipment', Brazilian Journal of Operations \& Production.
13(3), 252. https://doi.org/10.14488/BJOPM.2016.v13.n3.a3

Kruger, W., 2011, 'Addressing application software package project failure: Bridging the information technology gap by aligning business processes and package the information technology gap by aligning business processes and package
functionality', Unpublished master's thesis, Stellenbosch University, Stellenbosch.

Kruger, W., 2012, 'Strategic business-IT alignment of application software packages: Bridging the information technology gap', South African Computer Journal 49 1-11, viewed 02 October 2015, from http://sacj.cs.uct.ac.za/index.php/sacj/ article/viewArticle/90

Kruger, W. \& Rudman, R., 2013, 'Strategic alignment of application software packages and business processes using PRINCE2', The International Business \& Economics Research Journal 12(10), 1239-1260, viewed 02 October 2015, from https:// scholar.sun.ac.za/handle/10019.1/85449

Lee, Y., Shin, J. \& Park, Y., 2012, 'The changing pattern of SME's innovativeness through business model globalization', Technological Forecasting and Social Change 79(5), 832-842, https://doi.org/10.1016/j.techfore.2011.10.008

Li, W., Liu, K., Belitski, M., Ghobadian, A. \& O'Regan, N., 2016, 'e-Leadership through strategic alignment: An empirical study of small-and medium-sized enterprises in the digital age', Journal of Information Technology 31(2), 185-206. https://doi. org/10.1057/jit.2016.10 
Marcelino-Sádaba, S., Pérez-Ezcurdia, A., Echeverría Lazcano, A.M. \& Villanueva, P. 2014, 'Project risk management methodology for small firms', International
Journal of Project Management 32(2), 327-340. https://doi.org/10.1016/j. ijproman.2013.05.009

Matejun, M., 2014, 'The role of flexibility in building the competitiveness of small and medium enterprises', Management 18(1), 154-168, viewed 02 October 2015, from http://www.degruyter.com/view/j/manment.2014.18.issue-1/manment-20140012/manment-2014-0012.xml

Murray, A., 2011, White paper on PRINCE2 in one thousand words, vol. 2, The Stationery Office, viewed 30 October 2017, from http://www.best-managementpractice.com/gempdf/PRINCE2 in_One_Thousand_Words.pdf

O'Sheedy, D., 2012, 'A study of agile project management methods used for IT implementation projects in small and medium-sized enterprises', Published doctoral thesis, Southern Cross University, Lismore, viewed 30 October 2017 from http://epubs.scu.edu.au/theses/266/

Office of Government Commerce, 2004, Tailoring PRINCE2, The Stationery Office, UK. Office of Government Commerce, 2005, Managing successful projects with PRINCE2, The Stationery Office, UK.

Olugbode, M., Elbeltagi, I., Simmons, M. \& Biss, T., 2008, 'The effect of information systems on firm performance and profitability using a case-study approach', The Electronic Journal Information Systems Evaluation 11(1), 11-16, viewed 30 October 2017, from http://www.researchgate.net/profile/lbrahim_Elbeltagi/ publication/234015703_the_effect_of_information_systems_on_firm performance and_profitability_using_a_case_study_approach/ links/0fcfd50e480c041- b64000000.pdf

Saad, S., Ibrahim, A., Asma, O., Khan, M. \& Abdul, A., 2013, 'PRINCE2 methodology: An innovative technique of project management growing progressively across the globe', in 3rd International Conference on Business Management, pp. 1-22, viewed 30 October 2017, from http://cgr.umt.edu.pk/icobm2013/papers/Papers/ IC3-Jan-2013-049.pdf

Siegelaub, J.M., 2004, How PRINCE2 can complement PMBOK ${ }^{\circledR}$ guide and your PMP ${ }^{\circledR}$ APMG-International, viewed 30 October 2017, from http://ebooks.franciscomedina. net/taller_pmbok_prince2/prince2-complement-pmbok-pmp.pdf

Turner, J.R., Ledwith, A. \& Kelly, J., 2009, 'Project management in small to mediumsized enterprises: A comparison between firms by size and industry', International Journal of Managing Projects in Business 2(2), 282-296. https://doi.org/ 10.1108/17538370910949301

Turner, R., Ledwith, A. \& Kelly, J., 2012, 'Project management in small to medium-sized enterprises: Tailoring the practices to the size of company', Management Decision 50(5), 942-957. https://doi.org/10.1108/00251741211227627

Umble, E.J., Haft, R.R. \& Umble, M.M., 2003, 'Enterprise resource planning: Implementation procedures and critical success factors', European Journal of Operational Research 146(2), 241-257, viewed 02 October 2015, from http:// www.sciencedirect.com/science/article/pii/S0377221702005477

Verner, J.M. \& Evanco, W.M., 2005, 'In-house software development: What project management practices lead to success?', IEEE Software 22(1), 86-93, viewed 30 October 2017, from http://ieeexplore.ieee.org/xpls/abs_all.jsp?arnumber= 1377129\&tag $=1$

Viergever, N., 2014, 'PRINCE2 ${ }^{\oplus}$ in a nutshell', NVi Project Management, (November) pp. 1-5, viewed 30 October 2017, from http://www.viergever.info/en/download/ PRINCE2 in a nutshell.pdf

Wynn, M., Turner, P., Abas, H. \& Shen, R., 2009, 'Employment knowledge transfer to support IS implementation in SMEs', Industry \& Higher Education 23(2), 111-125. https://doi.org/10.5367/000000009788146629 


\section{Appendix 1: Summary of the Projects in Controlled Environments methodology}

Listed in the following table are the seven principles of PRINCE2 (Kruger 2011; Siegelaub 2004).

TABLE 1-A1: The seven principles of Projects in Controlled Environments.

\begin{tabular}{ll}
\hline Principle & Description of principle \\
\hline Continued business justification & $\begin{array}{l}\text { Throughout the project business } \\
\text { objectives, strategies and benefits should } \\
\text { remain aligned and documented as such. }\end{array}$ \\
$\begin{array}{ll}\text { Learning from experience } \\
\text { previous experience should be considered } \\
\text { and acted upon through the project. }\end{array}$ \\
Defined roles and responsibilities & $\begin{array}{l}\text { All individuals involved in the project } \\
\text { should have a clear understanding of what } \\
\text { is expected of them. }\end{array}$ \\
Managing by stages & $\begin{array}{l}\text { To properly control the project, it is } \\
\text { suggested that the project be } \\
\text { implemented in stages with sufficient } \\
\text { control points identified. }\end{array}$ \\
Managing by exception & $\begin{array}{l}\text { Each level of the project-management } \\
\text { team should have an authority limit based } \\
\text { on time, costs and scope. }\end{array}$ \\
Focusing on products & $\begin{array}{l}\text { Expected project deliverables as defined } \\
\text { in the project plan should remain the } \\
\text { main focus throughout the project. }\end{array}$ \\
\hline Tailoring to suit the project environment & $\begin{array}{l}\text { Themes and processes should be tailored } \\
\text { to suit the needs of the specific project. }\end{array}$ \\
\hline
\end{tabular}

Source: Office of Government Commerce 2005

Listed in the following table are the seven themes of PRINCE2 (Kruger 2011; Siegelaub 2004):

\begin{tabular}{ll} 
TABLE 2-A1: The seven themes of Projects in Controlled Environments. \\
\hline Theme & Description of theme \\
\hline Business case & $\begin{array}{l}\text { The business case can be defined as the main driver of the project. It } \\
\text { defines the expected benefits from the project deliverables. Should } \\
\text { it at any stage during project implementation appear that these } \\
\text { benefits are no longer there, termination of the project is to follow. }\end{array}$ \\
Organisation & $\begin{array}{l}\text { The roles and responsibilities of the project-management team } \\
\text { must be clearly laid out and the accountability structure should be } \\
\text { established. }\end{array}$ \\
Quality & $\begin{array}{l}\text { The expected quality of the project deliverables is to be clearly } \\
\text { defined and achieved in the end product through a quality system. }\end{array}$ \\
Risk & $\begin{array}{l}\text { Proper risk analysis and management techniques are to be used to } \\
\text { manage project risk throughout the project. }\end{array}$ \\
Planning & $\begin{array}{l}\text { Planning is essential for all projects; therefore, this theme sets out } \\
\text { the required steps to develop plans that are ultimately based on } \\
\text { the required deliverables of the project. }\end{array}$ \\
Changes & $\begin{array}{l}\text { Changes to the business cases and project deliverables during the } \\
\text { course of the project should be properly controlled and assessed } \\
\text { for relevant inclusion in the project plan. }\end{array}$ \\
& $\begin{array}{l}\text { The purpose of this theme is to monitor and compare outcomes with } \\
\text { planned deliverables set and to ensure that the project remains viable } \\
\text { in terms of the business case throughout the project. }\end{array}$ \\
\hline Progress
\end{tabular}

Source: Office of Government Commerce 2005

The seven processes of PRINCE2 are summarised as follows.

\section{Starting up a project (SU)}

This process occurs once at the start of a project lifecycle and is designed to ensure that the prerequisites for initiating the project are in place. The deliverable of this process, the project brief, sets out the reason for the project and what is required and should ideally be very short (Office of Government Commerce 2005:13). It includes the following (Kruger 2011:51):

- Appointing the project manager

- Including information on lessons learnt from previous projects, if available
- Appointing the project-management team

- Preparing the outline business case

- Choosing the correct approach for the project and draft the project brief

- Compiling the initiation stage plan.

\section{Directing a project (DP)}

This process includes the authorisation, monitoring and control of the project by the project board through various decision points. It includes the following (Office of Government Commerce 2005:14):

- authorising the start of the project (initiation)

- authorising the project

- authorising the stage or exception plan

- providing direction in terms of monitoring, giving advice and direction, reacting to threats and so on

- authorising the closure of the project.

\section{Initiating a project (IP)}

This process includes the planning of the project as a whole and entails the development of the project initiation document (Office of Government Commerce 2005:14). This document includes the benefits of the project for the business, the risks relating to the implementation of the project, the products that are developed from the project, activities included in the project lifecycle, the desired quality of the products and how resources will be applied throughout the project (Kruger 2011:54).

The initiating project further includes the following:

- preparing the risk management strategy

- preparing the configuration management strategy

- preparing the communication management strategy

- preparing project controls that are designed to detect deviations from the original project plan

- creating the project plan, which includes the costs, timeline and resources used in the project

- revising the original business case to include the costs, timelines and risks

- assembling the project initiation document.

\section{Controlling a stage (CS)}

In many cases, especially on larger projects, the project consists of various stages. Each stage is controlled separately on a day-to-day basis. This process details the control and monitoring procedures of the project manager during each stage (Office of Government Commerce 2005:15).

Each stage includes the following (Kruger 2011:55):

- authorising the work that is scheduled to be done for each stage

- reviewing the work that has already been done at various intervals

- reporting on the work completed

- documenting and escalating issues and risks identified during the stage

- taking any necessary corrective action. 


\section{Managing product delivery}

This process ensures that the planned product and deliverables are completed and handed over. It includes the following (Kruger 2011:56; Office of Government Commerce 2005:16):

- accepting the work being done and detailing what is required to be delivered. The team manager negotiates the details of the work packages with the project manager

- ensuring that the work is done as required

- ensuring that the work being conducted was conducted at the desired quality and delivering it to the project manager.

\section{Managing stage boundaries}

This process provides information to the project board on whether the deliverables were completed as planned during the stages. It also provides the board with information on whether it is viable to continue with the project. This process is there to assist the project board in authorising the completion of a stage and starting of the following stage (Office of Government Commerce 2005:15).

Activities within this process include the following (Kruger 2011:58; Office of Government Commerce 2005:15):

- assuring that all planned activities in the current stage have been completed successfully
- compiling and planning the next stage or execution plan by comparing it to the actual progress of the project

- revising the original project plan and updating the business case

- updating the risk logs and considering the viability of continuation of the project

- compiling an exception report for consideration and approval by the project board.

\section{Closing a project (CP)}

This process defines an organised closure of the project. The project manager compiles finalised information on the project for presentation to the board in order to obtain approval that the project may close (Office of Government Commerce 2005:16). Activities include the following (Kruger 2011:59-60; Office of Government Commerce 2005:17):

- ensuring that the aims and objectives as set out in the project-initiation document have been met

- determining whether deliverables have been delivered and accepted by the customer

- ensuring that arrangements were made for maintenance, operation and training of the delivered product

- compiling recommendations for future projects

- compiling an end project report and archiving all project files. 